\title{
Psychiatric disorders among the children of 5 to 18 years old of 'SIDR' affected areas
}

\author{
Mohammad SI Mullick', Jhunu Shamsun Nahar ${ }^{2}$, Nafia Farzana Chowdhury ${ }^{3}$ Wasima Rahman ${ }^{4}$, Mohammad \\ Monirul Islam ${ }^{5}$, MMA Shalahuddin Qusar ${ }^{6}$, M. Mahbubur Rahman ${ }^{7}$, Mohammad Shahidullah ${ }^{8}$ \\ ${ }^{1}$ Professor of Child and Adolescent Psychiatry and Chairman, Department of Psychiatry, ${ }^{2}$ Professor of Psychotherapy, Department of Psychiatry, ${ }^{3}$ Medical Officer, Department of Psychiatry, ${ }^{4}$ Medical \\ Officer, Department of Psychiatry, BSMMU ${ }^{5}$ Graded Specialist in Psychiatry Combined Military Hospital, Jessore Cantt., Jessore. ${ }^{6}$ Associate Professor, Department of Psychiatry,BSMMU.Dhaka. \\ ${ }^{7}$ Resident Psychiatrist Central Drug Addiction Treatment Center, Dhaka, ${ }^{8}$ Assistant professor, Department pf Psychiatry, Eastern Medical College, Comilla.
}

\begin{abstract}
:
Background Natural disasters give raise a significant amount of physical and mental impairment in human beings. Any sort of disaster acts as a causative and maintaining factor for any psychiatric morbidity. In November 15, 2007, the cyclone "SIDR" intensified to reach peak winds of $215 \mathrm{~km} / \mathrm{h}(135 \mathrm{mph})$ according to the IMD, a peak of $250 \mathrm{~km} / \mathrm{h}(155$ $\mathrm{mph}$ ) according to the JTWC. "SIDR" officially made landfall around 1700 UTC later that day, with sustained winds of $215 \mathrm{~km} / \mathrm{h}(135 \mathrm{mph})$.As it intensified to a Category 4-equivalent cyclone and thus coastal districts of Bangladesh faced heavy rainfall as an early impact of the cyclone. The damage in Bangladesh was extensive, including tin shacks flattened, houses and schools blown away and enormous tree damage. The entire cities of Patuakhali, Barguna and Jhalokati District were hit hard by the storm surge of over 5 meters $(16 \mathrm{ft}$ ). The head of the Red Crescent in Bangladesh expects the death toll to reach as high as 10,000 . Over 3,000 other fishermen were reported missing on over 500 fishing boats. The "SIDR" left its strong impact on those who survived . Objectives: The Study was aimed to estimate the prevalence of psychiatric disorder among children and adolescents in the "SIDR" affected areas. Method: This was cross sectional, qualitative study done among the children and adolescent groups of 5 to 18 years old to see the effect of natural disaster on the people of southern part of Bangladesh. The whole of the children population who attended in the health camp were included in the study during the study period. Three teams have worked among the four "SIDR" affected districts. Each team consists of Psychiatrists, General Physicians, and Clinical Psychologist. Results: A total of 158 children in four defined areas revealed that the prevalence rate of psychiatric disorder was $48 \%$. Conclusion: This type of study should be done in multi-centers in SIDR affected districts of Bangladesh to find out the actual prevalence rate of child and adolescent psychiatric disorder.
\end{abstract}

Key words: SIDR, Cyclone, Psychiatric Disorder.

[BSMMU J $2014 ; 7$ (1) : 20-26]

\section{Introduction:}

The name "SIDR" was contributed by Oman; it is an Arabic name of a tree belonging to the genus Ziziphus, specifically the Ziziphus spina-christi. There is another saying that it is derived from the Sinhalese Language where "SIDR" means 'hole' or 'eye.

Address for Correspondence: Mohammad SI Mullick Professor of Child and Adolescent Psychiatry and Chairman Department of Psychiatry

Mobile no: 01911288672,Email address: msimullick@gmail.com
On the morning of November 15, 2007, the cyclone "Sidr" intensified to reach peak winds of $215 \mathrm{~km} / \mathrm{h}(135$ $\mathrm{mph}$ ) according to the IMD, a peak of $250 \mathrm{~km} / \mathrm{h}(155$ $\mathrm{mph}$ ) according to the JTWC. Sidr officially made landfall around 1700 UTC later that day, with sustained winds of $215 \mathrm{~km} / \mathrm{h}(135 \mathrm{mph})$. It weakened quickly after landfall. As it intensified to a Category 4-equivalent cyclone on November 15, thousands of emergency officials were put on standby in eastern India and Bangladesh in advance of the storm's arrival. A total of 2 million 
people in Bangladesh evacuated to emergency shelters. Over 40,000 Red Cross volunteers were deployed to order residents in the 15 affected provinces into special cyclone and flood shelters. Coastal districts of Bangladesh faced heavy rainfall as an early impact of the cyclone. Dhaka and other parts of Bangladesh experienced drizzle and gusty winds. Total damages came close to $\$ 450$ million. The damage in Bangladesh was extensive, including tin shacks flattened, houses and schools blown away and enormous tree damage. Some local officials have described the damage as being even worse than that from the 1991 cyclone. The entire cities of Patuakhali, Barguna and Jhalokati District were hit hard by the storm surge of over 5 meters $(16 \mathrm{ft})$. About a quarter of the world heritage site Sunderbans were damaged. Much of the capital city of Dhaka was also severely affected, as electricity and water service were cut and significant damage was reported there due to winds and flooding. The local agricultural industry was also devastated, as many rice crops - which have a December harvest - were lost. At least 3,447 deaths have been reported. The hardest-hit area was Barguna, where 423 people were reported to have been killed according to local officials. Patuakhali was also hard-hit, with 385 deaths reported. Most of the deaths confirmed thus far were due to the winds, although 13 of them have been as a result of capsized boats in the Faridpur district of Bangladesh. The head of the Red Crescent in Bangladesh expects the death toll to reach as high as 10,000 . Over 3,000 other fishermen were reported missing on over 500 fishing boats.

Similarly, in between October 26 and November 4, 1998, Hurricane Mitch struck Central America, which was classified as a category 5 storm on the Saffir-Simpson scale and was the most deadly hurricane to strike the Western Hemisphere in the last two centuries. This hurricane caused massive destruction in Nicaragua and Honduras. Approximately 10,000 people were killed. Torrential rains fell at a rate of $1-2$ feet per day in many of the mountainous regions, resulting in massive floods and mudslides. Food and cash crops were largely wiped out. Hundreds of thousands of people were left without work and any means of income. Damage to basic infrastructure, agriculture production, and the industrial sector virtually destroyed more than two decades of progress in these countries. ${ }^{1}$ From another study, it is seen that Hurricane Andrew, one of the worst natural disasters ever to occur in the history of the United States. This Level 4 hurricane, with winds exceeding 160 miles per hour, destroyed or severely damaged over 125,000 homes in an area of 400 square miles, leaving 175,000 children and families temporarily homeless, bewildered, and without adequate food or supplies (Miami Herald Press, 1992). In the wake of such a devastating natural disaster, one could not help but wonder about the children. ${ }^{2}$ Victims of severe natural disasters such as tsunami almost always have horrific and traumatic experiences. Their reactions vary according to age and adaptation ability. The first survival response to trauma and threats was body biochemical change. It gradually changed overtime. Immediate mental shock, which resulted in reactions such as denial, blurring cognition, startled easily, usually lasted not more than 4 weeks. The symptoms beyond 4 weeks were diagnosed as Post traumatic stress disorder (PTSD). ${ }^{3,4,5,7}$

The Study was aimed to estimate the prevalence of psychiatric disorders among children and adolescents in the "SIDR" affected areas in Bangladesh.

\section{Methods:}

This was cross sectional, descriptive and qualitative study. The study was done among the children and adolescent groups of 5 to 18 years old of "SIDR" affected areas to see the effect of natural disaster on the people of southern part of Bangladesh. A total of three teams have worked among the four 'SIDR' affected districts, 1 in Potuakhali , 1 in Borguna, 1 in Pirojpur and Bagerhat district.

1. In Patuakhali and Barguna districts health camps were arranged for diagnosis Children and Adolescent psychiatric morbidity of that region. Treatment was given for psychiatric problems/disorders and physical problems.

2. In Pirojpur and Bagerhat districts a community survey was done for diagnosis Children and Adolescent psychiatric morbidity of those regions. Treatment was given for psychiatric problems/disorders and physical problems. 
Study priod and Areas Places visited : Patuakhali (Mirjagonj), Barguna (Betagi)

Duration: 26th to 29th January 2008, approximately 2 and half months after the SIDR struck. Places visited: Pirojpur (Vandaria), Bagerhat (Sharankhola) Duration: 16th to 19th March 2008, approximately 3 and half months after the SIDR struck.

Study Team: Each team consists of Psychiatrists, General Physicians, and Clinical Psychologist

Research instrument: Household and Disaster Questionnaire: That was a structured questionnaire, which contains socio demographic parameters including age, sex, education, information about family along with family structure, economic condition, social capital, and SIDR related losses.

The research assessment of psychiatric disorder was carried out using the Development and Well-Being Assessment (DAWBA).This uses a mixture of closed and open ended questions about child psychiatric symptoms and their impact. It was administered as an interview to parents, teachers and self (11years and above). The interviews were administered by interviewers who also record verbatim accounts of any reported problems, but do not rate them. Experienced clinicians subsequently review both verbatim accounts and answers to structured questions before assigning diagnoses according to ICD-10 or DSM IV criteria. Validated Bangla version of DAWBA was used in this study. ${ }^{8}$ The parent and self-version were administered. As the children attended in a center of medical help and the teacher version of DAWBA was not applied due to lack of opportunity of its applicability. In this study, DAWBA generated psychiatric diagnoses was only extended to Axis 1 psychiatric disorders of ICD-10 operational criteria. $^{9}$

\section{Sampling:}

- In Patuakhali and Barguna districts.

- The whole of the children population who attended in the health camp were included in the study during the study period. In total, 57 children and adolescents of both sexes within the age range between 5 and 16 years were included in this study. There was no exclusion criterion. Informed consent was taken and all the respondents agreed to participate in the study.

-We visited houses in the village of pirojpur and Bagerhat districts. The whole children population who was present in the house were included in the study during the study period. In total, 101 children and adolescents of either sex within the age range between 5 and 18 years were included in this study. There was no exclusion criterion. Informed consent was taken and all the respondents agreed to participate in the study.

Procedure: Household and Disaster Questionnaire was applied to the parents of child and adolescents after taking informed consent from the parents of children. Then parent version of DAWBA was applied to all parents. Self-version of DAWBA was administered to the children and adolescents, age 11 years and above. After completion of DAWBA questionnaire, the patients were diagnosed by the psychiatrist and treatment was given wherever it needed.

\section{Results:}

Analyses of a total of 158 children from 5-16 years old in four defined areas revealed that the total prevalence rate of psychiatric disorder was $48-10 \%$ (Table-I) .Overall prevalence of psychiatric disorder among 5-10 years old was $50.00 \%$ (Table-II) and among 11-16 years old was $54.54 \%$ (Table-III).Total prevalence of Psychiatric Disorders according to broad diagnostic categories were any disorder, any emotional disorders, hyperkinesis, behavioral disorders and developmental disorders which were $81.01 \%, 73.41 \%, 0.63 \%, 3,16 \%$ and $1,90 \%$ respectively (TableIV). Prevalence of Psychiatric disorders according to sex distributions in Potuakhali, Borguna, Bagerhat and Pirozpur among male respondents were $54.11 \%$ and among female respondents was $47.95 \%$ (TableV).Prevalence estimates for ICD-10 psychiatric disorders were stated with this broad categories and subcategories in (Table-VI). 
Table-I

Prevalence of psychiatric disorders among children and adolescent

\begin{tabular}{llllll}
\hline \multirow{2}{*}{ Disorders } & Potuakhali & Borguna & Bagerhat & Pirozpur & Total \\
& $\mathrm{N}=30(\%)$ & $\mathrm{N}=27(\%)$ & $\mathrm{N}=48(\%)$ & $\mathrm{N}=53(\%)$ & $\mathrm{N}=158(\%)$ \\
\hline Present & $13(43.33)$ & $14(51.85)$ & $25(52.04)$ & $24(45.28)$ & $76(48.10)$ \\
Absent & $17(56.67)$ & $13(48.15)$ & $23(47.96)$ & $29(54.72)$ & $82(51.90)$ \\
Total & $30(100.00)$ & $27(100.00)$ & $48(100.00)$ & $53(100.00)$ & $158(100.00)$ \\
\hline
\end{tabular}

Table-II

Prevalence of Psychiatric disorders among 5-10 years old

\begin{tabular}{llllll}
\hline \multirow{2}{*}{ Disorder } & $\begin{array}{l}\text { Potuakhali } \\
\mathrm{N}=26(\%)\end{array}$ & $\begin{array}{l}\text { Borguna } \\
\mathrm{N}=20(\%)\end{array}$ & $\begin{array}{l}\text { Bagerhat } \\
\mathrm{N}=34(\%)\end{array}$ & $\begin{array}{l}\text { Pirozpur } \\
\mathrm{N}=34(\%)\end{array}$ & $\begin{array}{l}\text { Total } \\
\mathrm{N}=114(\%)\end{array}$ \\
\hline Present & $11(42.30)$ & $10(50.00)$ & $17(50.00)$ & $19(55.88)$ & $57(50.00)$ \\
Absent & $15(57.70)$ & $10(50.00)$ & $17(50.00)$ & $15(44.12)$ & $57(50.00)$ \\
Total & $26(100.00)$ & $20(100.00)$ & $34(100.00)$ & $34(100.00)$ & $114(100.00)$ \\
\hline
\end{tabular}

Table-III

Prevalence of Psychiatric disorders among 11-16 years old

\begin{tabular}{llllll}
\hline \multirow{2}{*}{ Disorder } & $\begin{array}{l}\text { Potuakhali } \\
\text { Number(\%) }\end{array}$ & $\begin{array}{l}\text { Borguna } \\
\text { Number(\%) }\end{array}$ & $\begin{array}{l}\text { Bagerhat } \\
\text { Number(\%) }\end{array}$ & $\begin{array}{l}\text { Pirozpur } \\
\text { Number(\%) }\end{array}$ & $\begin{array}{l}\text { Total } \\
\text { Number(\%) }\end{array}$ \\
\hline Present & $02(50.00)$ & $04(57.14)$ & $08(57.14)$ & $10(52.63)$ & $24(54.54)$ \\
Absent & $02(50.00)$ & $03(42.86)$ & $06(42.86)$ & $09(47.37)$ & $20(45.46)$ \\
Total & $04(100.00)$ & $07(100.00)$ & $14(100.00)$ & $19(100.00)$ & $44(100.00)$ \\
\hline
\end{tabular}

Table-IV

Prevalence of psychiatric disorders according to broad diagnostic category*.

\begin{tabular}{llllll}
\hline Diagnostic category & $\begin{array}{l}\text { Potuakhali } \\
\mathrm{N}=30(\%)\end{array}$ & $\begin{array}{l}\text { Borguna } \\
\mathrm{N}=27(\%)\end{array}$ & $\begin{array}{l}\text { Bagerhat } \\
\mathrm{N}=48(\%)\end{array}$ & $\begin{array}{l}\text { Pirozpur } \\
\mathrm{N}=53(\%)\end{array}$ & $\begin{array}{l}\text { Total } \\
\mathrm{N}=158(\%)\end{array}$ \\
\hline Any Disorder & $21(70.00)$ & $14(51.85)$ & $43(89.58)$ & $50(94.34)$ & $128(81.01)$ \\
Any Emotional & $17(29.82)$ & $12(44.44)$ & $43(89.58)$ & $50(94.34)$ & $116(73.41)$ \\
Hyperkinesis & $01(3.33)$ & $00(0.00)$ & $00(0.00)$ & $00(0.00)$ & $01(0.63)$ \\
Behavioural & $03(10.00)$ & $00(0.00)$ & $01(34.72)$ & $01(01.88)$ & $05(3.16)$ \\
Developmental & $01(3.33)$ & $02(7.41)$ & $00(0.00)$ & $00(0.00)$ & $03(1.90)$ \\
\hline
\end{tabular}

*Co -morbidity was considered 


\section{Table -V}

Prevalence of psychiatric disorders according to sex

\begin{tabular}{|c|c|c|c|c|c|c|c|c|c|c|}
\hline \multirow[t]{3}{*}{ Disorder } & \multicolumn{2}{|c|}{ Potuakhali } & \multicolumn{2}{|c|}{ Borguna } & \multicolumn{2}{|c|}{ Bagerhat } & \multicolumn{2}{|l|}{ Pirozpur } & \multicolumn{2}{|l|}{ Total } \\
\hline & M & F & M & $\mathrm{F}$ & M & $\mathrm{F}$ & $\mathrm{M}$ & $\mathrm{F}$ & M & $\mathrm{F}$ \\
\hline & 11 & 2 & 7 & 7 & 11 & 14 & 17 & 12 & 46 & 35 \\
\hline Present & $(55.00)$ & $(20.00)$ & $(53.85)$ & $(50.00)$ & $(50.00)$ & $(53.85)$ & (56.66) & $(52.17)$ & $(54.11)$ & $(47.95)$ \\
\hline & 9 & 8 & 6 & 7 & 11 & & & 11 & 39 & \\
\hline Absent & $(45.00)$ & $(80.00)$ & $(46.15)$ & $(50.00)$ & $(50.00)$ & $(46.15)$ & (43.34) & (47.83) & $(45.89)$ & (52.05) \\
\hline Total & $\begin{array}{l}20 \\
(100)\end{array}$ & $\begin{array}{l}10 \\
(100)\end{array}$ & $\begin{array}{l}13 \\
(100)\end{array}$ & $\begin{array}{l}14 \\
(100)\end{array}$ & $\begin{array}{l}22 \\
(100)\end{array}$ & $\begin{array}{l}26 \\
(100)\end{array}$ & $30(100)$ & $\begin{array}{l}23 \\
(100)\end{array}$ & $\begin{array}{l}85 \\
(100)\end{array}$ & $\begin{array}{l}73 \\
(100)\end{array}$ \\
\hline
\end{tabular}

Table-VI

Prevalence estimate for ICD-10 psychiatric disorders *

\begin{tabular}{|c|c|c|c|c|c|}
\hline Diagnosis & $\begin{array}{l}\text { Potuakhali } \\
\mathrm{N}=30(\%)\end{array}$ & $\begin{array}{l}\text { Borguna } \\
\mathrm{N}=27(\%)\end{array}$ & $\begin{array}{l}\text { Bagerhat } \\
\mathrm{N}=48(\%)\end{array}$ & $\begin{array}{l}\text { Pirozpur } \\
\mathrm{N}=53(\%)\end{array}$ & $\begin{array}{l}\text { Total } \\
\mathrm{N}=158(\%)\end{array}$ \\
\hline Any Disorder & $21(70.00)$ & $14(51.85)$ & $43(89.58)$ & $50(94.34)$ & $128(81.01)$ \\
\hline Any Emotional Disorder & $17(56.66)$ & $12(44.44)$ & $43(89.58)$ & $50(94.34)$ & $116(73.41)$ \\
\hline Separation anxiety disorder(SAD) & $02(6.66)$ & $01(3.71)$ & $01(2.08)$ & $02(3.77)$ & $06(03.80)$ \\
\hline Specific phobia & $00(0.00)$ & $02(7.41)$ & $11(22.92)$ & $15(28.30)$ & $28(17.72)$ \\
\hline Social phobia & $00(0.00)$ & $00(0.00)$ & $01(2.08)$ & $01(1.89)$ & $02(01.27)$ \\
\hline Panic attacks/agoraphobia & $00(0.00)$ & $01(3.71)$ & $03(6.25)$ & $02(3.77)$ & $06(03.80)$ \\
\hline $\begin{array}{l}\text { Post Traumatic Stress Disorder } \\
\text { (PTSD) }\end{array}$ & $11(36.67)$ & $06(22.22)$ & $22(45.83)$ & $22(41.51)$ & $61(38.61)$ \\
\hline $\begin{array}{l}\text { Obsessive } \\
\text { Compulsive Disord er(OCD) }\end{array}$ & $01(3.33)$ & $00(00.00)$ & $01(2.08)$ & $00(00.00)$ & $02(01.27)$ \\
\hline $\begin{array}{ll}\text { Generalized } & \text { Anxiety } \\
\text { Disorder(GAD) } & \end{array}$ & $00(0.00)$ & $01(3.71)$ & $00(0.00)$ & $01(1.89)$ & $02(01.27)$ \\
\hline $\begin{array}{l}\text { Major } \\
\text { Disorder(MDD) }\end{array}$ & $04(13.33)$ & $01(3.71)$ & $05(10.42)$ & $01(1.89)$ & $11(06.96)$ \\
\hline Hyperkinesis & $01(3.33)$ & $00(0.00)$ & $00(0.00)$ & $00(0.00)$ & $01(00.63)$ \\
\hline Any Behavioural disorder & $03(10.00)$ & $00(0.00)$ & $01(34.72)$ & $01(01.88)$ & $05(03.16)$ \\
\hline Oppositional defiant disorder & $00(0.00)$ & $00(0.00)$ & $01(2.08)$ & $01(1.89)$ & $02(01.27)$ \\
\hline Conduct disorder & $03(3.33)$ & $00(0.00)$ & $00(0.00)$ & $00(0.00)$ & 03(01.90) \\
\hline Any developme ntal disorder & $01(3.33)$ & $02(7.41)$ & $00(0.00)$ & $00(0.00)$ & 03(01.90) \\
\hline Mental retardation & $00(0.00)$ & $02(7.41)$ & $00(0.00)$ & $00(0.00)$ & $02(01.27)$ \\
\hline Tic disorder & $01(3.33)$ & $00(0.00)$ & $00(0.00)$ & $00(0.00)$ & $01(00.63)$ \\
\hline Autistic spectrum disorder & $00(0.00)$ & $00(0.00)$ & $00(0.00)$ & $00(0.00)$ & $00(00.00)$ \\
\hline
\end{tabular}

\section{Discussion:}

In Bangladesh community based first exploratory epidemiological study among children and adolescent reported $15.2 \%$ prevalence of child and adolescent psychiatric disorder. ${ }^{8}$ The prevalence of present study is much higher than this report that certainly reflects the adverse effect of 'SIDR' in the child mental health. In SIDR affected areas, prevalence of any psychiatric disorder was $81.01 \%$.(8) In community survey; prevalence of any anxiety disorder was $8 \%$ whereas in "SIDR" affected areas it was
$73.41 \%{ }^{(8)} \quad$ In community survey, prevalence of separation anxiety disorder (SAD) was $1.5 \%$ but in SIDR affected areas it was $3.8 \% .{ }^{(8)}$ Prevalence of specific phobia in community survey was $1 \%$ whereas in this study it was $17.72 \%{ }^{(8)}$ In community survey, post traumatic stress disorder (PTSD) was 1.3\% but in "SIDR" affected areas, it was found $38.61 \%{ }^{(8)}$ In community survey, prevalence of any Behavioral disorder was $8.9 \%$ but in "SIDR" affected areas it was $1.9 \%$. ${ }^{(8)}$ In community. survey, any developmental disorder was found $0.2 \%$ but 
-unity survey, prevalence of any Behavioral disorder was $8.9 \%$ but in "SIDR" affected areas it was $1.9 \% .{ }^{(8)}$ In community survey, any developmental disorder was found $0.2 \%$ but in SIDR affected areas it was $1.9 \%{ }^{\left({ }^{(8)}\right.}$ From a study in 2004 in Thailand, it was found that the prevalence of PTSD among tsunami victims was $57.3 \%$ at 6 weeks after the disaster. It declined sharply at 2 years after the event. Despite receiving financial, rehabilitation and mental health support, $2.7 \%$ of the victims continued to suffer from PTSD 5 years after the disaster. ${ }^{11}$

The severity of children's symptoms depends on factors such as level of exposure to the event, personal injury, loss of loved ones, level of parental support, and dislocation. Moreover, other factors significantly associated with PTSD symptoms included delayed evacuation, fearing that they or their family members' life was in danger and extreme panic. The older children and those who feared that they or their family members' life was in danger were more significantly associated with depressive symptoms. ${ }^{12}$

Another study shows that among 94 children, 47 (50\%) had at least one psychiatric diagnosis: posttraumatic stress disorder (PTSD) was 33\%; major depression was 9.6\%; adjustment disorder was $9.6 \%$, and separation anxiety disorder was $3.2 \%$. The psychiatric diagnoses, specifically PTSD, were significantly associated with the child's age and exposure to the traumatic events. ${ }^{12}$

After about 1-4 months of "SIDR", the people of the cyclone-hit area suffer from Psychiatric problems and disorders at a high level. It is necessary to deliver essential mental health service to these people to ensure the integrated and holistic health of this people. Usually these group of people with mental problems \& disorders need to have professional consultation with Psychiatrist/Clinical Psychologist/Psychotherapist at weekly or quarterly interval. From a study, it was seen that the incidence of PTSD, in other parts of the world, has been reported to be $6-25 \%$ after a disaster or a crisis. It is believed that the PTSD rate is highly dependent on severity of the disaster encountered, level of family and community devastation and rescue effectiveness and quality. ${ }^{13}$
We propose professional consultations at weekly intervals for the victims of Cyclone/other man-made or natural disaster. A multi-disciplinary team can work in a locality in each day of the week. If the team resides in a District /Thana headquarters, they can cover 5-6 localities of that District/Thana. These disaster-affected people will need integrated psychiatric services for at least 12 months, which might have to be extended to 24-36 months. The needs for food, shelter and physical treatment are main requirements for the disaster-hit people for the first 4 weeks. We think that there is demand for the work of an integrated Psychosocial Team from the start of 3rd week.

A standard Psychosocial Team will require 1-2 Psychiatrist(s), 3-4 Clinical Psychologists, 1-2 people from other required disciplines. The Psychiatrists can work as the Team leader. But new decisions may be taken by institutional seniority (work experience). The management can decide about the Team leader at the time of construction. The list of local NGOs who are prepared and competent to participate and facilitate the work of the Psychosocial Team, have to be kept prepared so that this list becomes readily available at the time of need. The list of works of every discipline group has to be made well demarcated. The daily essential functions like decisions about food, lodging, transport etc can be distributed among these specialty groups. The residence of Multidisciplinary Team have to be well fitted/well-equipped and made at the District or Thana Headquarter. We need to construct a well-planned referral system placing the psychosocial teams at the root and tertiary level hospitals at the top. Every locality should have a designated service delivery point and a day of the week will have to be allocated for that locality. The Government Mental Health Service has to be integrated with this proposed Emergency Multi-disciplinary team. Government health service delivery points at the disaster-hit places should have necessary medications (antidepressants, anxiolytics, sedatives etc.) for storage and delivery on demand. The list of necessary medications for disaster-hit people will have to be prepared by a group of experts from Bangladesh Association of Psychiatrists and Disaster Response Team. The duties of everyone of the Psychosocial Team have to be kept written and made easily available on demand and it has to be available in the internet. The priority-based list of volunteering Psychiatrists, Clinical 
Psychologists and allied manpower have to be prepared and they have to be well trained through continued training and education. The aims and objectives, methods of functioning, list of participants/volunteers, current and past activities, results obtained from previous work, email, postal address etc. of the Disaster Response Multidisciplinary Team have to be made available online and have to be updated at regular interval. As the team is multi-disciplinary and members come from different background, we need to adopt a code of conduct among the members of the team to ensure good working environment. The government must develop appropriate public health guidelines and protocols for standardizing emergency health operations in the country, as well as for promoting best public health practice in humanitarian crisis situations. The Government should develop epidemiological tools and indicators for trend analysis of the post-flood health situation in the country including setting up an early warning system for detecting an unusual incidence of exotic diseases. Mental health professionals should work together to provide the necessary mental health supports during a disaster. They have to provide additional support and services for persons with severe mental illness during the time of a disaster.

\section{Conclusion:}

The study was conducted to find out the psychiatric disorder among child and adolescents in two small areas of southern part of Bangladesh where "SIDR" struck. As the sample size was small it does not reflect actual figure of prevalence rate. This type of study should be done in multi-centers in SIDR affected districts of Bangladesh to find out the actual prevalence rate of child and adolescent psychiatric disorder.

\section{References:}

1. Armen K, Goenjian, Luis M, Alan M, Steinberg, Lynn A. Fairbanks, Maria L.A, Haig A, Goenjian R.S, Pynoos. Posttraumatic Stress and Depressive Reactions Among Nicaraguan Adolescents After Hurricane Mitch. Am J Psychiatry 2001; 158:
788-794.

2. Annette M, La G, Wendy K, Silverman,Mitchell J. Symptoms of Posttraumatic Stress in Children After Hurricane Andrew: A Prospective Study .Journal of consulting and clinical psychology, 1996 ;64( 4) 712-723.

3. American Academy of Child and Adolescent Psychiatry. Practice parameters for the assessment and treatment of children and adolescents with posttraumatic stress disorder. J Am Acad Child Adolesc Psychiatry 1998; 37: 4S-26S.

4. Galantc R. Foa D. An epidemiological study of psychic trauma and treatment effectiveness for children after a natural disaster. J Am Acad Child Psychiatry 1986; 25:357-63.

5. Yule W, Bolton D, Udwin O, Boyle S, O'Ryan D, Nurrish J. The long-term psychological effects of a disaster experienced in adolescence: I: The incidence and course of PTSD. J Child Psychol Psychiatry 2(H) 0; 41:503-11.

6. Lee I, Ha YS, Kim YA, Kwon YH. PTSD symptoms in elementary school children after Typhoon Rusa. Taehan Kanho Hakhoe Chi 2004; 34:636-45.

7. McDermolt B.M, Lee EM, Judd M, Gibbon P. Posttraumatic stress disorder and general psychopathology in children and adolescents following a wildfire disaster. Can J Psychiatry 2005; 50:137-43.

8. Mullick M, Goodman R. The prevalence of psychiatric disorders among 5-10 year olds in rural, urban and slum areas in Bangladesh. Soc Psychiatry Psychiatr Epidemiol 2005; 40:663-71.

9. World Health Organization (1993) The ICD-10 Classification of mental and behavioral disorders: diagnostic criteria for research. World Health Organization, Geneva

10. Vinadda $P$, Panom K, Ratanotai $P$, Sirirat U, Nantawat $S$, Nattorn P, Pornjira P, Tiraya L, Nattince C, Ketsiri L, Nisarat W, Janarpar S, Thanyalak W, Chukial Y, Pranee P, LukkanaT, Peerayut C, Naratip S. Post-traumatic Stress Disorder in Children after the Tsunami Disaster in thailand: A 5-Year FoUow-Up:J Med Assoc Thai 2011; 94 (3): 138-144.

11. Thienkrua W, Cardozo BL, Chakkraband ML,Guadamuz TE, Pengjuntr W, Tantipiwatanaskul P,et al. Symptoms of posttraumatic stress disorder and depression among children in tsunamiaffected areas in southern Thailand. JAMA 2006; 296:549-59.

12. Piyavhatkul N, Pairojkul S, Suphakunpinyo C. Psychiatric disorders in tsunami-affected children in Ranong province, Thailand. International Journal of the Kuwaity university Health Scince Center.2008; 17(4):290-5.

13. American Academy of Child and Adolescent Psychiatry. Practice parameters for the assessment and treatment of children and adolescents with posttraumatic stress disorder. J Am Acad Child Adolesc Psychiatry 1998; 37 (10 Suppl): 4S-26S. 